\title{
Designing an innovative professional development experience to build infection control professionals' educational expertise
}

\author{
Gwyneth L. Meyers, $\mathrm{PhD} ;{ }^{1}$ Michele Jacobsen, $\mathrm{PhD}^{2}$ Elizabeth Henderson, $\mathrm{PhD}^{3}$ \\ ${ }^{1}$ Senior Clinical Practice Coordinator, Infection Prevention and Control, Alberta Health Services, Calgary, AB, Canada \\ 2 Professor and Vice Dean, Werklund School of Education, University of Calgary, Calgary, AB, Canada \\ ${ }^{3}$ Professor Emeritus, Department of Community Health Sciences, University of Calgary, Calgary, AB, Canada
}

\section{Corresponding author:}

Gwyneth L. Meyers

Infection Prevention and Control

Alberta Health Services

Room 3683A Peter Lougheed Centre

350026 Ave N.E., Calgary, AB T1Y 6J4 Canada

Tel.: 403-943-4157

gwyneth.meyers@ahs.ca

\section{ABSTRACT}

Background: Advances in networked learning technologies have impacted our understanding and organization of teaching and learning. In the modern context of a learning society, conventional classroom-style education and transfer of knowledge is being challenged. Infection prevention and control (IPAC) educational practice must respond to the changes that technology brings to teaching and learning. While education is an important component of IPAC professional practice, few Infection Control Professionals (ICPS) have formal pedagogical training. ICPs need support in shifting from teaching-as-telling approaches to becoming designers of contemporary active and engaged teaching and learning environments.

Methods: To build ICP pedagogical expertise and practice within the Alberta Health Services (AHS) IPAC program, a Design-Based Research methodology was used to systematically engineer an intentionally disruptive professional development experience (PDE) for ICPs that aligned with contemporary teaching and learning strategies. The PDE was situated in the context of a Community of Learning $(\mathrm{CoL})$ located within the ICPs' workplace practice. Learning in the CoL was mediated through participation in collaborative design, teaching, and learning activities over a period of one year.

Results: The PDE framework that emerged in this study facilitated changes in the AHS ICP CoL participants' understanding of teaching and learning, their sense of identity as educators, and their educational practices. The core of the framework focused on designing for a flexible, responsive collaborative learning environment supported by four strategies: a) creating an awareness of ICP educational practice, b) building pedagogical knowledge, c) experiencing different teaching and learning strategies, and d) building ICPs' identity as educators.

Discussion: Creating conceptual change and new designs for teaching practice is not easy, as it involves significant transformation that can be uncomfortable and complex and often requires new ways of learning. This paper discusses the guiding principles used in the design of this intentionally disruptive yet positive and responsive learning experience to build the participating ICPs' pedagogical expertise and practice.

\section{KEYWORDS}

Infection prevention and control; education; teaching and learning; professional development; instructional design

\section{INTRODUCTION}

This paper, the last in a series of four, describes the design, development, and implementation of an innovative professional development experience (PDE) for Infection Control Professionals (ICPs) within the Alberta Health Services (AHS) Infection Prevention and Control (IPAC) Program. The PDE sought to facilitate a paradigm shift in how ICPs think about and practice education in response to a call for action described in the first paper in this series [1]. The PDE was informed by and designed to respond to ICPs' requests for opportunities to build their educational expertise and address their challenges, as described in the third paper in this series [2]. In response to many influences such as learning technologies, major changes are taking place regarding contemporary teaching and learning processes and it is important that ICPs build the necessary

Acknowledgements: This research would not have been possible without the ongoing support of the Alberta Health Services Infection Prevention and Control Program and the participation of the Infection Control Professionals in that program.

Conflicts of interest: None.

Funding: There was no formal funding for this research. Alberta Health Services provided Group Learning Initiatives Funding. Funds from competitive Alberta Health Services Learning and Professional Development Awards in 2012, 2013, and 2014 addressed some of the costs associated with this research.

Ethics approval: This research was conducted as part of a larger doctoral research study that received ethical approval from the University of Calgary's Conjoint Health Research Ethics Board. 
pedagogical expertise they need to respond to these changes.

Advances in technology, including the growing prevalence of networked mobile devices, have impacted our understanding and organization of teaching, including the place, space, and pace of where and how learning occurs [3-5]. One result is a greater focus on the concept of a learning ecology with increased attention to instructional design and what it means to learn $[6,7]$. The workplace is increasingly becoming a place of learning, much of which occurs through informal learning processes [8]. Healthcare delivery is also becoming more complex, requiring learning that enables healthcare workers (HCWs) to adapt to ever-changing work environments and generate new knowledge to continuously improve their practice [9]. In the context of a modern learning society, and with the need for lifelong learning, conventional classroom-style education based on knowledge transfer is being challenged, particularly in workplace settings [10].

Learning in the twenty-first century requires a shift away from educational delivery informed by behaviourist philosophies that have objectivist roots. Such approaches treat knowledge as objective, independent, and external to an individual. From this perspective, education is an organized, pre-planned activity with specifically defined outcomes that take place within an individual [11]. Important shifts regarding contemporary educational approaches have emerged in recent decades. These shifts have been informed by constructivist theoretical frameworks such as Lev Vygotsky's Zone of Proximal Development, Yrjö Engeström's Activity Theory, and Jean Lave and Étienne Wenger's Situated Learning [12-14]. Such constructivist learning theories hold that learning not only takes place within an individual, but is also embedded in the context and culture in which learning occurs and is mediated by activity within such systems [13-15]. Socially situated collaborative approaches to learning expand the idea of knowledge transfer to the individual to include the idea of socially distributed knowledge building between and among groups [16-18].

Education is an important component of IPAC professional practice and a core competency for ICPs [19]. ICPs spend a significant amount of time providing repeated education and training to HCWs on core IPAC principles [20]. However, few ICPs have formal pedagogical training. ICPs rely primarily on conventional teacher-centric information-giving modes of teaching but find the design, delivery, and evaluation of such educational approaches both challenging and troublesome [2]. Effective education calls for active, interest-based learning by HCWs situated in the constantly changing environments and social contexts in which they work. ICPs need support in making these shifts in their teaching and learning practices because the changes involved require modifying how ICPs work with disciplinary knowledge, embrace educational technologies, and design educational environments for learning.

\section{METHODS}

The main objective of this research was to build ICP pedagogical knowledge, expertise, and practice within the AHS IPAC program with a view to facilitating a conceptual shift from commonly held conventional and passive approaches of education as information transfer to more active and engaged teaching and learning environments. To achieve this, a Design-Based Research (DBR) methodology was used to systematically engineer an intentionally disruptive PDE that aligned with constructivist teaching and

\section{FIGURE 1: Overview of the Community of Learning's structure and organization.}

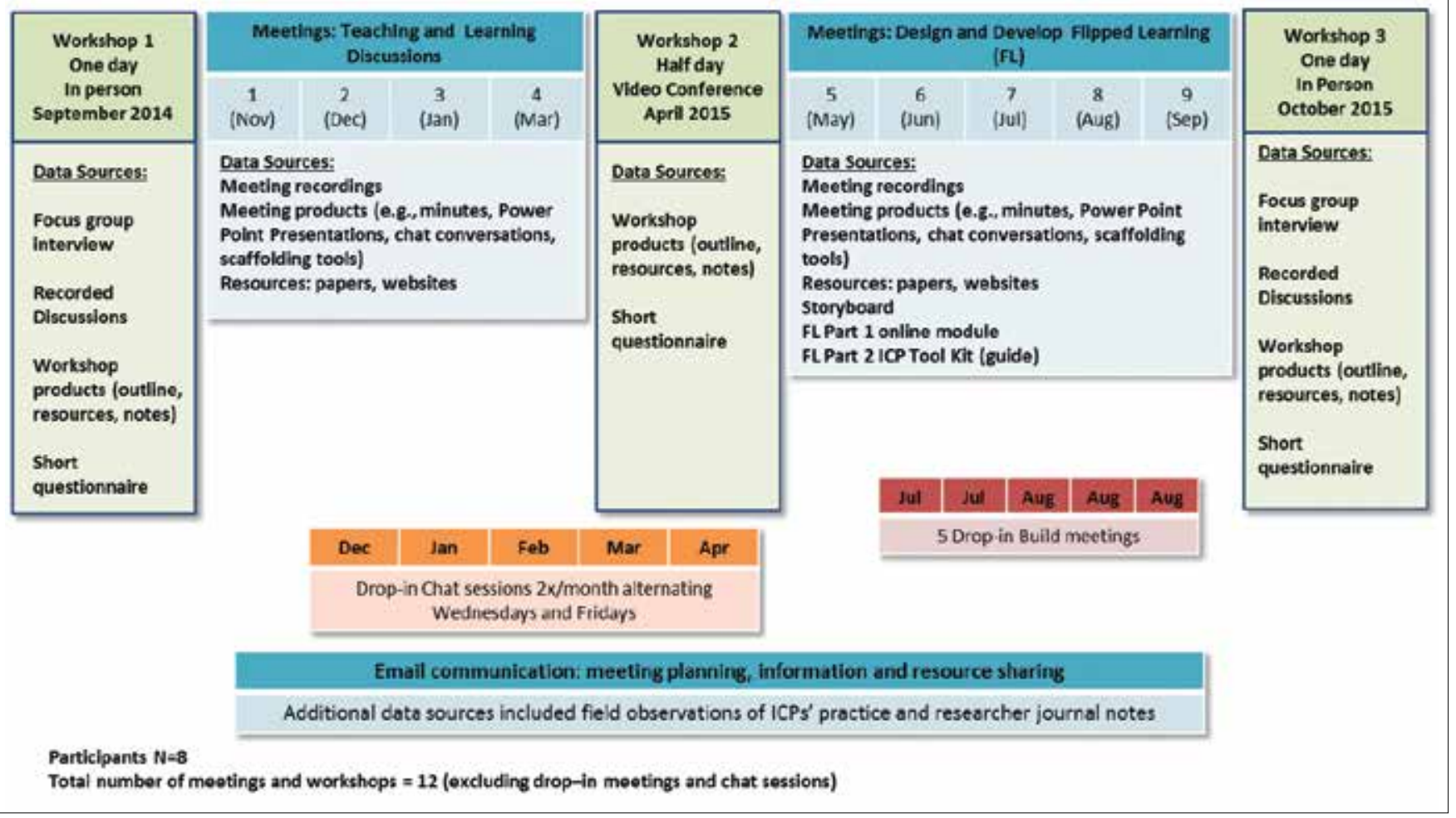


learning approaches. DBR is an innovative, complex, changeoriented research methodology that emerged from the field of the Learning Sciences [21]. In DBR, the research is embedded in both theory and practice, which are used together throughout the research process to inform the design, development, and implementation of an intervention to address an identified problem. This theoretical and practical grounding of the research necessitates collaborative researcher-practitioner partnerships that incorporate expert advice based on the experience and practice wisdom of the participants, which help shape the research and the many decisions taken throughout the research process. As the research progresses, the intervention is modified through a series of iterative cycles. Emerging data is analyzed and reflected upon and new designs are created and implemented. In this way, not only is the intervention refined in context, but the theory upon which the intervention is based is extended, facilitating a better understanding of how and why the intervention does or does not work to address the identified problem. A DBR approach balances rigor with relevance, allowing for flexibility and responsiveness to emerging issues while maintaining a research focus as the study evolves. A detailed explanation of the DBR methodology is provided in the second paper in this series [22].

Participants for the PDE were recruited via email between June and August 2014 from a convenience sample of 87 full-time

\begin{tabular}{|c|c|}
\hline Domain Content & Examples of Content Topics \\
\hline Teaching and Learning Concepts & $\begin{array}{l}\text { - Behaviourism, Constructivism, and Cognitivism } \\
\text { - Learning theories and models } \\
\text { - Instructional Design } \\
\text { - Collaborative and situated learning } \\
\text { - Communities of Inquiry (Col) and Communities of Practice (CoP) } \\
\text { - Learning in virtual environments }\end{array}$ \\
\hline Elements of Instructional Design & $\begin{array}{l}\text { - ADDIE model (Analyze, Design, Develop, Implement, Evaluate) } \\
\text { - Domains of learning: cognitive, affective, and psychomotor } \\
\text { - Benjamin Bloom's Taxonomy } \\
\text { - Writing effective learning objectives } \\
\text { - Design principles for developing multimedia learning environments } \\
\text { - Robert Gagné's nine events for e-learning } \\
\text { - Storyboarding } \\
\text { - Learning Management Systems and Sharable Content Object Reference Model }\end{array}$ \\
\hline Constructivist Activities & Examples of Content Topics \\
\hline $\begin{array}{l}\text { Discussing concepts in workshops } \\
\text { and meetings }\end{array}$ & $\begin{array}{l}\text { - ICPs engaged in small and large group discussions on a variety of topics to explore } \\
\text { their understanding and applicability to IPAC teaching. } \\
\text { - Researcher modelled different approaches to facilitating discussion. } \\
\text { - ICPs reflected on their own educational practices and experiences, including their } \\
\text { experiences with Ebola teaching and training. }\end{array}$ \\
\hline $\begin{array}{l}\text { Playing the online public health } \\
\text { game Outbreak at Watersedge }{ }^{1}\end{array}$ & $\begin{array}{l}\text { During the first workshop, to experience learning using technology, ICPs explored } \\
\text { learning in a virtual environment by playing an online game in pairs and then } \\
\text { discussed their experiences as a larger group in the context of learning concepts. }\end{array}$ \\
\hline $\begin{array}{l}\text { Collaboratively designing a learning } \\
\text { experience for ICPs to teach HCWs }\end{array}$ & $\begin{array}{l}\text { - After experiencing FL as learners, together the ICPs then designed, developed, } \\
\text { implemented, and evaluated an FL experience they and other AHS ICPs could use to } \\
\text { teach HCWs. This collaborative activity was the core interventionist experience of the CoL } \\
\text { professional development experience. }\end{array}$ \\
\hline
\end{tabular}


ICPs employed by the AHS IPAC program. Eight self-selected ICPS volunteered to participate with permission from their directors, which ensured formal support and time for the ICPs to participate in the PDE during working hours.

The resulting PDE, which took place over 13 months between September 2014 and October 2015, was situated in the context of a Community of Learning (CoL) located in the ICPs' workplace practice. Figure 1 illustrates the final organizational structure of the CoL that evolved from a series of iterative modifications during the study. The CoL involved three workshops, held at the beginning, the middle, and the end of the PDE, and nine online meetings. The first and last workshops were day-long face- to-face events. Workshop 2 was a half-day video conference. There were nine scheduled online meetings and several informal online drop-in meetings and chat sessions throughout the PDE. Additional communication occurred via email to plan and share information and resources.

To build their educational knowledge, the ICPs engaged in several collaborative teaching and learning activities. The educational concepts explored and activities used in the CoL are summarized in Table 1.

The core activity was to invite the ICPs to create and implement an FL experience that all AHS ICPs could use for teaching HCWs. FL is a pedagogical strategy that blends online

\section{TABLE 2: Design strategies used in the Community of Learning experience.}

\begin{tabular}{|c|c|}
\hline Design Strategies & Explanation of the Design Strategy \\
\hline Design-Based Research [22] & $\begin{array}{l}\text { - The ICPs' practice wisdom and experience informed decision-making regarding the } \\
\text { design of the CoL. } \\
\text { - Theory and practice woven together to intentionally and iteratively inform the CoL's } \\
\text { ongoing design. } \\
\text { - Collaborative partnership between researcher and the ICP participants facilitated } \\
\text { responsive design solutions to identified problems and emerging local issues. }\end{array}$ \\
\hline
\end{tabular}

\begin{tabular}{l|l} 
Blended Learning [23] & - Learning experience integrated face-to-face and online interaction, taking advantage of
\end{tabular} affordances offered by both instructional approaches.

- Use of Blended Learning (BL) responded to ICPs' requests for PDEs regarding the use of technology for teaching.

- Embedding the CoL in the ICPs' workplace practice facilitated their ability to situate and model learning using familiar technologies (e.g., Microsoft Lync@), videoconference, and the Internet).

- BL supported both synchronous and asynchronous interactions and a flexible learning environment.

Collaborative Learning [24, 25]

- ICPs worked together as a group to discuss and solve problems with supporting learning-by-doing that was socially situated to facilitate distributed knowledge building across the group.

Cognitive Apprenticeship [26]

Approaches used to enable ICPs learning to acquire, develop, and use cognitive tools through activity:

- Pedagogical content: ICPs were provided with foundational knowledge with which to build their understanding of teaching and learning and a vocabulary to enable reflection on and discussion about their teaching and learning experiences.

- Scaffolding: ICPs were provided with structures to facilitate completion of tasks, including objectives, timelines, resources, and exemplar documents to guide practice and activities.

- Role modelling: Researcher made teaching concepts and approaches visible by verbalizing her thinking while performing tasks so ICPs could visualize and observe the tasks and processes involved.

- Sequencing: Learning activities were ordered with increasing complexity and diversity over time to assist ICPs' knowledge building and skill development.

Community of Inquiry [23]

In collaborative learning environments, the higher-order thinking needed for transformative learning is facilitated by the interrelationship of:

- Social presence, which builds group cohesion and trust through open, respectful communication and discourse.

- Cognitive presence, which cultivates and facilitates deep, meaningful learning through information sharing, connecting, applying, and questioning ideas.

- Teaching presence, which involves the creation of a learning environment in which the teaching function can be taken on by any member of the group. This was facilitated in the group by shaping the constructive exchange of information and fostering an environment of critical thinking and problem-solving. The researcher planned and led most of the teaching activities in the CoL. The ICPs took on teaching functions during these activities by sharing their educational experience and practice wisdom from their IPAC professional practice and their attempts to implement what they were learning in the $\mathrm{CoL}$ in their practice outside the CoL. 
and face-to-face learning by rearranging how time is spent both in and out of a classroom-type setting [5]. Prior to being asked to create an FL experience, the CoL ICPs participated in an FL strategy designed and delivered by the researcher. This FL strategy was used to teach the ICPs about instructional design in online multiuser environments, and also to model the use of FL and have the ICPs experience learning within this type of teaching method.

Several design strategies - such as blended learning, collaborative learning, cognitive apprenticeship principles; the Col principles of social, cognitive, and teaching presence; and the DBR approach itself - were used to shape the CoL experience. A summary explanation of how each of these design elements was used is provided in Table 2.

As DBR embraces the concept of triangulation, multiple data collection methods were used over the course of the $\mathrm{CoL}$ to cross-check results for consistency, to inform subsequent activities, and to enhance the confidence of the research findings. These data sources are summarized in Figure 1.

The use of focus group interviews conducted by the researcher at the beginning and end of the CoL enabled the collection of before-and-after data to assess processes and changes in educational understanding and practice through participation in the CoL. The focus group interviews were also useful for bringing the participants together to explore shared experiences, generate new ideas within a social context, and facilitate team learning through self-disclosure and interaction in focused discussions [27-29]. The specific intent of the first focus group interview was to collect qualitative data to gain a deeper understanding of the ICPs' educational experiences, expertise, beliefs, attitudes, and understanding regarding their educational practices. The specific intent of the second focus group interview at the end of the CoL was to have the participants reflect on their learning and experience in the CoL as well as to evaluate the CoL by outlining challenges they encountered and to make suggestions for improvement. Question guides, with a series of open-ended questions, were used to conduct the focus group interviews.

In addition to the focus group interviews, participants were asked to complete a short paper-based questionnaire at the end of each of the three workshops. The questionnaire comprised two open-ended questions: the first asked ICPs to identify and comment on three key learnings, while the second asked them to identify and comment on any challenges they were experiencing. Responses helped to identify the participants' learning progress as well as to inform the next steps in the design and development of the PDE.

Data collected from focus group interviews and short questionnaires was based on self-report, and thus was subject to the risk of under- or over-reporting of issues by participants. To study actual behaviour and ideas or concepts made explicit in the self-reported data, field observations of a subset of the CoL ICPs' educational practices were conducted by the researcher. These observations were carried out while the ICPs provided education to HCWs in their various home sites outside of the context of the CoL. The researcher took the role of non-participant observer and used a paper-based tool to record these observations. The observation tool, informed by the concept of a learning ecology, facilitated the documentation of relationships amongst the instructor, learners, content, teaching strategies, technologies used, and the learning environment.

In DBR, a deeper understanding of the phenomena under investigation can develop while the research is in progress. Consequently, it is important to systematically and comprehensively document and record the data and the design progress [7]. Where possible, all conversations occurring during focus group interviews and various $\mathrm{CoL}$ activities and meetings were recorded and transcribed for analysis. These recordings, as well as meeting documents, emails, teaching plans, and other resources produced in the $\mathrm{CoL}$, provided rich sources of data.

Researcher journals kept throughout the study also proved to be valuable data sources. At the outset of the study, a set of criteria was created to guide the journaling process. Transparency was facilitated by methodically documenting communications, procedures, processes, and problems identified during the research, including how such problems were responded to and accounted for. This documentation was important given that the intimate involvement of the researcher in the DBR process is recognized as a potential challenge for the researcher [30, 31]. The collaborative researcher-participant relationship resulted in the researcher needing to manage the roles of researcher, educator, and colleague in the CoL. The data from the journals helped clarify these roles, track the complex sequence of events, and understand how and why the multiple design decisions that occurred in the study contributed to the credibility and trustworthiness of the research.

In addition to the use of multiple data sources to make connections between intended and unintended outcomes, member checking, external audits, and expert opinion were employed to further ensure trustworthiness and credibility of the research. Member checking involved regularly asking participants for their feedback on data interpretation and findings to assess their representativeness, completeness, and fairness throughout the study. Regular discussions with fellow researchers regarding decisions, next steps, and emerging findings provided objective feedback that also enhanced the credibility and trustworthiness of the research. External audits of data and activities were conducted by a research assistant. The research assistant took notes and observed individual (including the researcher) and group interactions during all workshop activities. These notes and observations were reviewed after each workshop and were also treated as data sources.

As data were collected, they were cleaned and entered into Microsoft Excel(C and QSR NVivo 10@ for analysis. A systematic process, informed by the principles of grounded theory, was used for coding and to identify emerging themes [32, 33]. Four analysis cycles occurred during the study. The first cycle was a preliminary data analysis that occurred after each CoL activity was completed to iteratively inform the next steps in the design of the CoL. The second cycle was a sequential, time-based approach that analyzed the data in the order that it was collected after all data collection was completed. This facilitated collation and synthesis of data and resulted in the identification of several broad, overarching categories. The third analysis cycle involved 
a thematic approach. All data sources were re-examined and recoded under the categories identified in the second cycle to further synthesize and integrate data. This facilitated the development of explanatory relationships between themes. The fourth cycle of analysis occurred while writing about the themes. During this phase, identified relationships were refined into visual diagrams and models.

\section{RESULTS}

\section{Description of CoL participants}

The eight CoL ICP participants worked in all five AHS zones across the province, which included both urban and rural settings as well as acute, continuing, and community healthcare sectors.

The participants' years of experience in IPAC varied and they came to IPAC with training in a variety of professional backgrounds, including microbiology, epidemiology, and nursing. Some of the participants had experience teaching in nursing programs and colleges, and most had engaged with clinical nurse educators in the various portfolios they covered. While three reported some education training as a part of their degrees, the ICPs indicated that most of their training as teachers was experiential based on practice, trial and error, observing others, and obtaining feedback from learners. The key reasons ICPs identified for participating in the $\mathrm{CoL}$ were because there was "no formal training for educating in IPAC" and "the desire to be part of a group to share experiences and learning," as "ICPs often educate in isolation."

\section{Impact of the CoL: What ICPs learned}

The ICPs reported several learning outcomes from participation in the CoL, which aligned with three themes: a) developing awareness, b) learning about learning, and c) learning in community. They reported developing a greater awareness of their own and AHS IPAC program teaching processes and where they were in relation to those processes. The ICPs reported that the IPAC Program relied primarily on the use of PowerPoint "as the unspoken but expected approach" for teaching: "This is how our department does things and sends messages out." One ICP indicated that learning about pedagogical concepts created awareness by making her implicit practices explicit: "I often used elements of adult principles and didn't know that they were a thing!" The ICPs reported becoming aware of different teaching strategies, beyond those they had been using, which provided them with resources and ways to change their practice: "I think that coming to IPAC it felt like I needed to use PowerPoint but now I know it is okay to use other methods and it works." The ICPs also reported becoming more aware of the importance of their role as educator, noting that "one of the main things is that we're all kind of in the same boat so it's nice to know that you're not alone" and that "There are others who yearn to become better educators." Developing increased awareness of diverse practices enabled the ICPs to understand and reflect on their present educational practices in order to make changes.

In addition to increasing their awareness of educational practices, the ICPs indicated they "learned about learning." ICPs reported learning new terms such as "transformative learning," that there were "different teaching strategies to facilitate learning, and these approaches could be used for different reasons," and that "designing for teaching was important to facilitate learning, rather than just focusing on content." They also reported that it was "easy to be complacent and focus on content, forgetting the value in knowing how to do our teaching." They valued learning that "research[-]validated approaches to more effective teaching" existed. Exposure to research literature both affirmed and validated their frustrations regarding surface approaches to education.

Learning about learning in community resonated strongly with the ICPs. They identified the value and importance of being able to share, support, and learn from each other in the context of community: "We are stronger and better together" and "We're all experiencing a lot of the same challenges." They valued discussion that was "open, free[-]flowing, comfortable and honest." The ICPs talked about group cohesion in terms of "camaraderie" and having "an appreciation for each other." They talked about wanting to "continue to grow, learn and work together."

Diversity of voice in the context of community was also important to ICPs and they valued "being able to hear different perspectives." The benefits of shared experience included being able to strategize together and being supported by their connectedness. Emotionally, ICPs felt sustained by each other: "It's quite energizing, to hear all the different voices and sort of hear echoes of what I was thinking." The ICPs talked about connecting ideas by "obtaining insights I had not considered" and remarked that group discussions often provided "closure to ideas." Over the course of the CoL, the ICPs formed a group identity, which speaks to the value and importance of collaborative learning. They also appreciated being able to "put their learning into practice through activity." The ICPs noted that by working collaboratively, they shared the workload. Working as a group was easier than working individually. The shared workload helped support them in attending to their other work responsibilities while working to achieve CoL deadlines. The collaborative design offered flexibility, and the core FL project could keep moving forward while individual ICPs could come and go, getting caught up and learning from the group upon their return.

\section{Impact of the CoL: What changed}

In addition to growing awareness, learning about learning, and experiencing new teaching and learning concepts, the ICPs also identified that their perception of themselves as teachers and their teaching practices had changed. At the end of the CoL, the ICPs talked about being more comfortable with seeing themselves as educators. As one ICP noted, "I believe, at the beginning, most of us wouldn't talk about ourselves as teachers." While exploring their identity as educators, the ICPs found being called an educator either "intimidating" or "empowering" or both. Being empowered was viewed as positive, being able to influence others, and having good resources and tools to be more effective at facilitating learning and engaging learners. Being intimidated, on the other hand, was linked to an "imposter syndrome, kind of 
almost like you're pretending." ICPs felt like they were educating but did not feel qualified: "Anyone can educate, but not everyone is an educator." They noted that being an educator is an expected core competency in the IPAC profession, but they did not feel they possessed that competency. While they taught as part of their role, they felt the formal role of educator goes unrecognized because it is embedded in their consultative practice.

To shift from intimidation to empowerment in their educator role, ICPs reported needing to develop awareness and ownership of their educator role, to make their implicit educational role explicit, and to acquire teaching and learning knowledge and experience. Their identity as educator was linked to feeling competent and having expertise. As one ICP noted, "I feel like I have some authority behind my opinions. It's not just opinion[;] now it's backed by a bit of research and theory [... and] I can kind of spew out some of those key words and talk about them." Research-informed practice led to a sense of validation in the ICPs' educator roles. The ICPs valued acquiring resources because these provided a context and language for understanding their teaching and learning practices. These resources were practical tools that would support continued growth and ability to implement new teaching strategies. The ICPs also discovered resources in each other, drawing on each other's knowledge and experiences. Figure 2 summarizes the issues regarding ICPs' identity as educators and how they shifted from feeling intimidated to empowered in that role.

The ICPs reported that the shift in their identity as teachers and their thinking about teaching and learning also changed their teaching practices. Gaining insight into their role and teaching practices, greater understanding of pedagogical concepts, and a language to understand their practices helped the ICPs to begin to modify their practices. Modifications included shifting from relying on PowerPoint to incorporating more interactive components in their teaching.

Initial field observations of ICP educational practice conducted prior to or near the beginning of the CoL supported the findings from the self-reported data that ICPs tend to use a teacher-centric approach to their education. ICPs' teaching focused on providing information using PowerPoint. When case scenarios were embedded in their presentations, the ICPs used a traditional question-and-answer style of interaction with the learners, resulting in limited learner engagement. The types of incremental practice changes reported by the CoL ICPs were corroborated by the later field observations. Two of the CoL ICPs' practices were observed after the completion of the CoL. Both of the observations were of formal in-service education sessions. While both of the ICPs still employed an overall teacher-centric information-giving approach, both had modified their approaches to include interactive activities interspersed throughout the sessions. The nature and application of learner activities suggested more attention was being given to designs for learning rather than information-giving. While both ICPS still used PowerPoint, the content in slides did not focus on a series of facts or information. One ICP used the PowerPoint technology to design a learning activity in which learners took control of the technology and used a drag-and-drop feature to document the other learners' responses to an IPAC scenario. The other ICP incorporated a video on vaccination to promote discussion and invited learners to work together in small groups to discuss issues they had each observed in the video. The small groups were then asked to share highlights of their discussion with the larger group. Both ICPs achieved greater HCW engagement in their education sessions by moving away from reliance on information-giving via PowerPoint and conventional

FIGURE 2: Issues related to ICPs' identity as educators.

\section{ICP Educator Identity}

\begin{tabular}{|l|}
\hline Intimidating \\
\hline - Not an expert in education \\
- Role is implicit and not recognized \\
- Imposter syndrome \\
- Expected Competency but: \\
○ No expertise \\
O No formal training \\
O No confidence \\
O No resources \\
- Perceptions: \\
O Education is not effective \\
Not rewarding \\
Questioning how to facilitate \\
learning to influencing \\
practice
\end{tabular}

Becoming Aware:

- Acknowledging and owning role and identity

Acquiring expertise:

- Teaching and learning knowledge and experience

- Tools and resources

Changing practice:

- Understanding processes

- Using more effective strategies that move knowledge into practice

\section{Empowering}

- Affirmation of formal role

- Educator includes title, role and doing the activity

- Qualified expert

- Role is explicit and recognized:

o Has expertise

- Formal training

- Confidence

o Resources

- Perceptions:

- Education is positive and rewarding

- Facilitating learning and influencing practice

- Engaging learners 
question-and-answer approaches and toward learning activities designed to engage learners in discussions and debates with each other.

ICPs moved from designing content to designing more for learning. As one ICP shared, "I loved the comment, 'If you can't change the content, change the method of delivery.' A lot of what we need to teach them can be dry, but the way we teach doesn't have to be." Another ICP noted, "I didn't give much thought before to lesson planning. And now I give more thought to learning style and just sort of thinking more about the learning than just thinking about the tasks, the outcomes." The ICPs also reframed how they perceived learners. For example, one ICP stated, "I guess I don't see learners in the same way, throwing information at them as empty vessels. I now see them as having more responsibility for their learning. Maybe now thinking about them being invested enough in the information that they actually feel sort of empowered by it."

Although ICPs indicated they had more confidence in planning education, they noted that this was different than having confidence in actually applying and practicing it: "So I guess I have more confidence in the planning and presentation of myself as an educator, not in doing education." The ICPs identified that these newer approaches take more time and are more demanding of them but felt they would result in greater satisfaction from achieving better outcomes. They reported that change was challenging, and there was an element of discomfort in moving out of practices with which they were comfortable. Their response was to take smaller steps by integrating more interactive activities in their education sessions and relying less on PowerPoint, using it more as a guide instead. The ICPs reported moving toward more open, participatory education. As they did so, they found the experiences more rewarding.

\section{The process of learning and change in the CoL}

The ICPs described the CoL learning experience as positive and rich despite the fact that it was more involved than they had expected. They indicated participating in the CoL was "not like attending a conference, workshop, or course where your role is to be a student." The ICPs indicated learning was achieved through disruption of their thinking, by experiencing a different style of learning, applying that different style, and challenging their perceptions of themselves. The constructivist experience was not always easy. The ICPs noted that it could be "challenging, difficult, and sometimes confusing," reporting that they "had to learn new learning processes themselves." Figure 3 summarizes the interventionist pedagogical design framework that emerged from the CoL PDE that facilitated a shift in the ICPs' thinking and understanding of learning and changes to their teaching practices.

Community was at the core of the framework. To create a positive, responsive, and collaborative learning community, the CoL design attended to fostering the concepts of social, cognitive, and teaching presence (see Table 2 for descriptions of social, cognitive, and teaching presence). This facilitated emotional support and a sense of belonging through the social relationships that were built based on open, honest communication and sharing and a sense of collective responsibility and accountability in the group. This also supported flexibility in responding to the ICPs' IPAC practice needs. This was particularly important because the $\mathrm{CoL}$ was situated in the context of the ICPs' workplace, with all the entailing demands and upheaval.

Within the CoL framework, four main strategies informed the building of the ICPs' pedagogical expertise: 1) creating an awareness of ICP educational practice, 2) building ICP pedagogical knowledge, 3) experiencing different teaching and learning strategies, and 4) building identity as educators.

FIGURE 3: An interventionist professional development framework to facilitate change in ICP educational understanding and practice.

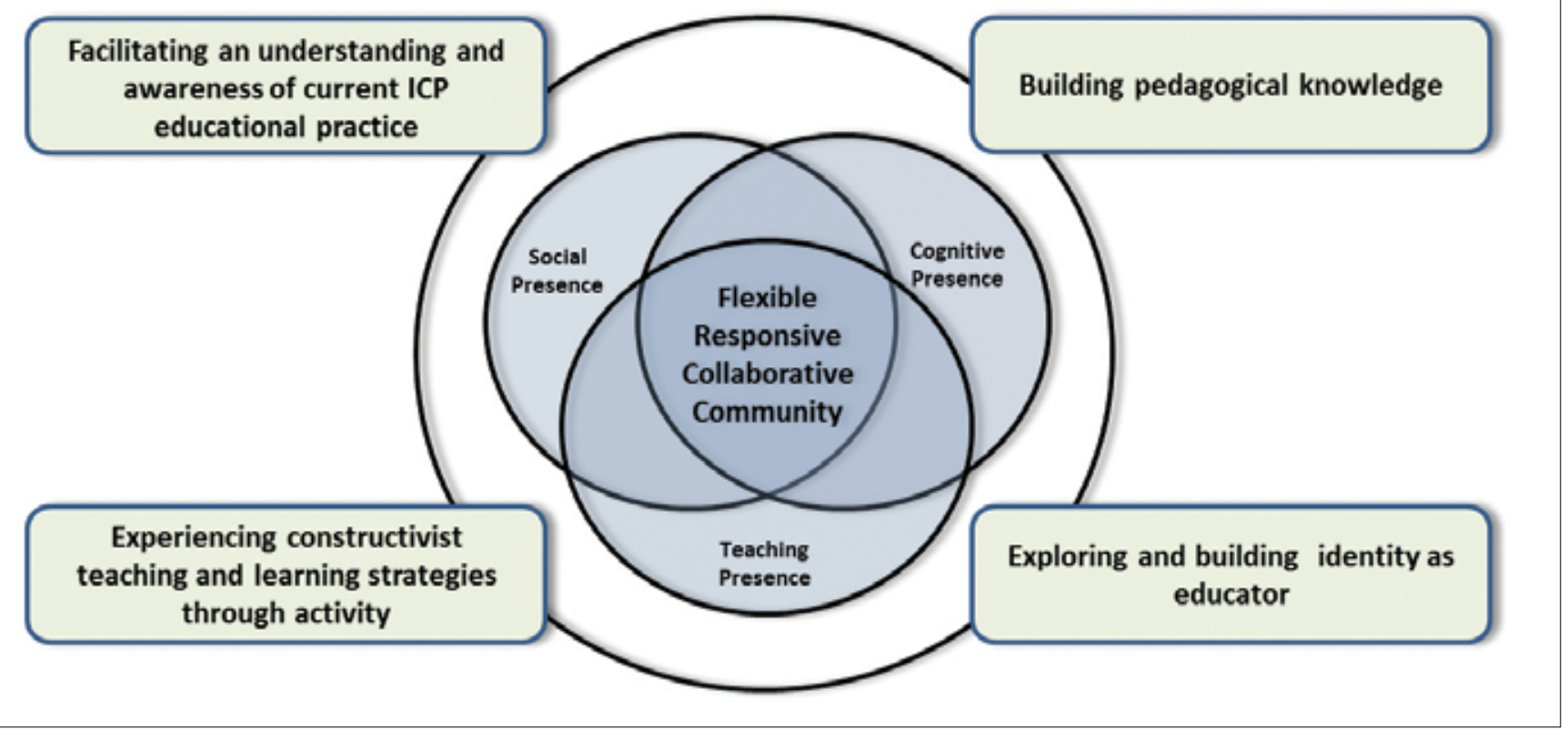


Facilitating the ICPs' awareness of their educational practice and making their underlying assumptions about that practice explicit was achieved through reflection and discussion. This enabled the ICPs to identify key teaching and learning challenges and to understand the reason for and nature of those challenges in order to have intentional and informed dialogue regarding possible solutions to address those challenges.

To have informed dialogue, the ICPs needed pedagogical knowledge, a vocabulary, and a conceptual framework with which to discuss and reflect on their problems and possible solutions. This was accomplished by providing the ICPs with pedagogical content, scaffolding their learning experiences, and sequencing learning activities and role modelling to make those pedagogical concepts and experiences more explicit.

To achieve deeper learning, the ICPs needed to apply their knowledge. The ICPs were therefore engaged as learners to collaboratively use different teaching and learning strategies so they could better understand the strategies through lived experience. ICPs also experienced the value of distributed knowledge building through involvement in and reflection on experiences in the CoL.

Lastly, in order to be open to new approaches and perspectives for teaching and learning, the ICPs needed to embrace their identity as educators. This required opportunities to make their implicit educator role explicit and recognize they were not alone or isolated in their educator role or practices. Opportunities to build their identity as educators through the acquisition of knowledge, resources, experience, and pedagogical language led to ICPs feeling more validated and empowered in modifying and making changes to their practice.

\section{Limitations}

Due to this study's small sample size, the findings may be reflective of this particular study group's educational training and experience and may differ if repeated elsewhere. Also, the unique nature of the AHS organization must be considered, as healthcare is a provincial responsibility. Organizational policies and procedures vary between provinces and territories and the IPAC programs within them, potentially impacting IPAC educational culture and teaching practices. The findings and design framework that emerged from this study are based on the first macro cycle of the DBR methodology contributing primarily to local practice and theory. DBR is a long-term research process requiring a series of macro cycles to upscale local theory to achieve more generalizable, higher-level theory for the broader ICP population and for ICP educational practices in general. For these reasons, additional cycles will need to be conducted to refine the emerging theory and educational professional development framework. Further testing of the design framework in the context of other IPAC programs will be important.

\section{DISCUSSION}

The notion of conceptual change embodies the idea that learners must build new ideas in the context of old ones, emphasizing change rather than the acquisition of knowledge [34]. Significant learning, such as that involved in conceptual change, is not easy [15]. Transformative learning requires the disruption of belief systems, attitudes, and behaviours. Incorporating new ideas and concepts can be uncomfortable and disconcerting. The PDE framework described in this paper outlines a set of guiding principles to facilitate the creation of an intentionally disruptive yet positive and responsive learning experience to promote change in ICPs' educational practice.

To accommodate the demands of the workplace in which the PDE was situated, it was necessary to design for responsiveness and flexibility. Flexiblility is a key instructional design consideration in collaborative learning communities so that the learning environment can be responsive to the complex nature of the teaching and learning process. The designer of the learning environment also needs the flexibility to adjust the learning design within the teaching and learning goals to negotiate emerging and unexpected events [23, 35].

Because the PDE was focused on situated learning in community, consideration was given to the learning environment in which the learners interacted and the concepts and resources provided [36]. The Col framework, comprising social, cognitive, and teaching presence, provided a useful conceptual structure to support the design of the learning environment [23]. Col concepts align naturally with the ICPs' workplace practice. ICPs regularly work collaboratively in teams with various stakeholders to solve problems such as those encountered during outbreaks (social presence). ICPs draw on scientific evidence and best practice to make decisions (cognitive presence) and they often engage in coaching and mentoring each other (teaching presence) as they cross-cover each other's areas of specialty. It is not surprising, therefore, that using the various Col presences worked well in designing the CoL environment.

Designing for sociality in the learning environment is important to consider in future CoL experiences, especially given the importance the ICPs gave to this aspect of the CoL and because the social dynamics will likely vary with different groups of ICPs. It has been reported that the nature of social, cognitive, and teaching presence may change with different learner profiles [37]. The ICPs identified that the activities in the CoL did not just disrupt their thinking, but also required that they learn different ways of learning. Accordingly, individual learner attributes and abilities, in particular the ICPs' approach to learning and need for sociality, need to be considered in designing future iterations of the CoL.

The CoL instructional design focused on developing learning by the community as opposed to by the individual. Knowledge building at the community level focuses on the idea of knowledge creation and advancement through idea improvement and developing knowledge that is deeper and richer, akin to understanding the "how and why" of something, not just the "what" [18]. To facilitate such collaborative knowledge building, it was important to focus on meaningmaking (i.e., making sense of constructivist teaching and learning processes situated as ICP educators) through joint activity $[13,38]$. This necessitated designing activities that involved creation and evaluation, which require higher-order thinking, as described in Bloom's revised taxonomy [39]. 
Acquiring knowledge of learning concepts and teaching strategies provided the ICPs with a pedagogical vocabulary with which to dialogue about their educational practice. This articulation was helpful for learning, as it made reflection and metacognition about the process for teaching and learning possible, giving ICPs the ability to reframe their educational challenges and to identify potential solutions [21]. Discussion in the CoL supported learning through argumentation as the ICPs debated and questioned their ideas and experiences, working together to make sense of the ideas they were encountering in relation to their educator role and practice. Argumentation has been identified as an effective method for learning as it not only facilitates making knowledge explicit, but can also facilitate conceptual change and co-elaboration of new knowledge [40]. Such discussions, grounded in an understanding of the ICPs' current educational practice, provided a foundation on which to build pedagogical knowledge. Grounding the learning in the ICPs' prior knowledge and experience made the new information more relatable and relevant, a key principle of adult learning [41].

The need to build the ICPs' identity as educators emerged during the DBR iterative process and became an important design principle. Because learning transforms who we are and what we do, it is an experience of empowering identity [42]. The process of "becoming" is not simply a matter of the acquisition of knowledge and skills; it is a process of transforming knowledge within a context. Therefore, the development and affirmation of the ICPs' identity as educators was supported by engaging in situated learning activities to develop ICP educational expertise as part of a community.

Participation in the CoL PDE resulted in changes in the ICPs' understanding of teaching and learning, their sense of identity as educators, and changes in their teaching practices. Upon completion of the PDE, several of the ICPs who participated in the CoL participated in the creation of an AHS ICP education CoP to continue developing their educational expertise and practice along with other ICPs in the AHS IPAC program. The findings and local changes resulting from this research, while positive and successful, constitute an important first step toward the greater goal of building ICP educational expertise and practice in the profession generally. The IPAC profession would benefit from developing partnerships with educational experts from the Learning Sciences to further our educational understanding and research. By building such expertise, our understanding of the value, relevance, and effectiveness of IPAC educational practices can be re-evaluated and IPAC educational research can be opened to new discoveries and advances in teaching and learning to improve our ability to effect behavioural change among HCWs.

\section{REFERENCES}

1. Meyers, G. L., Jacobsen, M., \& Henderson, E. (2018). An exploration of IPAC educational intervention research: What do we mean by education? Candian Journal of Infection Control, 33(2), 89-95. Retrieved from https://prism.ucalgary.ca/ bitstream/handle/1880/109281/2018_An_exploration_of_IPAC. pdf?sequence $=1$ \&isAllowed $=y$
2. Meyers, G. L., Jacobsen, M., \& Henderson, E. (2018). Understanding infection control professionals' educational practice: There is more to it than meets the eye. Canadian Journal of Infection Control, 34(4), 198-203.

3. Robinson, R., Molenda, M., \& Rezabek, L. (2008). Facilitating learning. In A. Januszewski \& M. Molenda (Eds.), Education technology: A defintition with commentary (15-48). New York, NY: Routledge Taylor Francis Group.

4. Sawyer, R. K. (2007). Optimising learning : Implications of learning sciences research. In OECD/CERI learning in the 21st century: Research, innovation and policy. Paris: Centre for Educational Research and Innovations. Retrieved from http://www.oecd.org/site/ educeri21st/40554221.pdf

5. Johnson, L., Adams Becker, S., Cummins, M., Estrada, V., Freeman, A., \& Hall, C. (2016). Horizon report: 2016 higher education edition. Austin, TX: New Media Consortium. Retrieved from http://cdn.nmc. org/media/2016-nmc-horizon-report-he-EN.pdf

6. Normak, P., Pata, K., \& Kaipainen, M. (2012). An ecological approach to learning dynamics. Journal of Educational Technology \& Society, 15(3), 262-274. Retrieved from https://www.jstor.org/stable/ jeductechsoci.15.3.262

7. Cobb, P., Confrey, J., Lehrer, R., \& Schauble, L. (2003). Design experiments in educational research. Educational Researcher, 32(1), 9-13. Retrieved from https://www.jstor.org/stable/3699928

8. Le Clus, M. A. (2011). Informal learning in the workplace: A review of the literature. Australian Journal of Adult Learning, 51(2), 355-373. Retrieved from https://ro.ecu.edu.au/cgi/viewcontent. cgi? referer $=$ https://www.google.com/\&httpsredir $=1 \&$ article $=1152 \& \mathrm{co}$ ntext $=$ ecuworks2011

9. Fraser, S. W., \& Greenhalgh, T. (2001). Coping with complexity : Educating for capability. British Medical Journal, 323(7316), 799-803. doi: https://doi.org/10.1136/bmj.323.7316.799

10. Manuti, A., Pastore, S., Scardigno, A. F., Giancaspro, M. L., \& Morciano, D. (2015). Formal and informal learning in the workplace: A research review. International Journal of Training and Development, 19(1), 1-17. doi: 10.1111/ijtd.12044

11. Schuh, K. L., \& Barab, S. (2008). Philosophical perspectives. In J. M. Spector, M. D. Merrill, J. Van Merrienboer, \& M. P. Driscoll (Eds.), Handbook of research on educational communications and technology (3rd ed., 67-82). New York, NY: Lawrence Erlbaum.

12. Vygotsky, L. S. (1978). Mind in society: The development of higher psychological processes. Cambridge, MA: Harvard University Press.

13. Greeno, J. G., \& Engeström, Y. (2014). Learning in activity. In R. K. Sawyer (Ed.), The Cambridge handbook of the learning sciences (2nd ed., 128-147). New York, NY: Cambridge University Press.

14. Lave, J., \& Wenger, É. (1991). Situated learning: Legitimate peripheral participaiton. New York, NY: Cambridge University Press.

15. Illeris, K. (2007). How we learn: Learning and non-learning in school and beyond. New York, NY: Routledge Taylor Francis Group.

16. Gresalfi, M., Barab, S., \& Sommerfeld, A. (2012), Intelligent action as a shared accomplishment. In D. Y. Dai (Ed.), Design research on learning and thinking in educational settings (41-64). New York, NY: Routledge Taylor Francis Group.

17. Scardamalia, M., \& Bereiter, C. (1994). Computer support for knowledge-building communities. Journal of the Learning Sciences, 3(3), 265-283. Retrieved from https://www.jstor.org/stable/1466822

18. Scardamalia, M., \& Bereiter, C. (2014). Knowledge building: Theory, pedagogy, and technology. In R. K. Sawyer (Ed.), The Cambridge handbook of the learning sciences (2nd ed., 97-115). New York, NY: Cambridge University Press.

19. Moralejo, D., Catt, B., Ashcroft, M., Christou, H., DeFalco, K., Dyck, B., \& Rhodenizer-Rose, S. (2016, October 7). IPAC Canada core competencies for infection control professionals. Retrieved from https:// ipac-canada.org/photos/custom/Members/pdf/2016_IPAC_Canada CoreCompetenciesforlCPs.pdf

20. IPAC Canada. (2016, November 2). Infection prevention and control core competencies for health care workers: A consensus document. 
Retrieved from https://ipac-canada.org/photos/custom/pdf/HCW Core_Competency_Category_Table-2016November(2).pdf

21. Sawyer, R. K. (2014). The new science of learning. In R. K. Sawyer (Ed.), The Cambridge handbook of the learning sciences (2nd ed., 1-20). New York, NY: Cambridge University Press.

22. Meyers, G. L., Jacobsen, M., \& Henderson, E. (2018). DesignBased Research: Introducing an innovative research methodology to infection prevention and control. Canadian Journal of Infection Control, 33(3), 158-164. Retrieved from https://ipac-canada.org/ photos/custom/CJIC/CJIC_Fall2018_Meyers.pdf

23. Vaughan, N. D., Cleveland-Innes, M., \& Garrison, D. R. (2013). Teaching in blended learning environments: Creating and sustaining communities of inquiry. Edmonton, AB: Athabasca University Press.

24. Satwicz, T., \& Stevens, R. (2008). A distributed perspective on collaborative activity. In J. M. Spector, M. D. Merrill, J. Van Merrienboer, \& M. P. Driscoll (Eds.), Handbook of research on educational communications and technology (3rd ed., 163-171). New York, NY: Lawrence Erlbaum.

25. Scardamalia, M., \& Bereiter, C. (2014). Knowledge building and knowledge creation: Theory, pedagogy, and technology. In R. K. Sawyer (Ed.), The Cambridge handbook of the learning sciences (2nd ed., 397-417). New York, NY: Cambridge University Press.

26. Collins, A., \& Kapur, M. (2014). Cognitive apprentiship. In R. K. Sawyer (Ed.), The Cambridge handbook of the learning sciences (2nd ed., 109-127). New York, NY: Cambridge University Press.

27. Breen, R. L. (2006). A practical guide to focus-group research. Journal of Geography in Higher Education, 30(3), 463-475. doi: 10.1080/03098260600927575

28. Kern, D. E. (2009). Introduction. In D. E. Kern, P. A. Thomas, \& M T. Hughes (Eds.), Curriculum development for medical education: A six step approach (2nd ed., 1-4). Baltimore, MD: Johns Hopkins University Press.

29. Krueger, R. A., \& Casey, M. A. (2000). Focus groups: A practical guide for applied research (3rd ed.). Thousand Oaks, CA: Sage Publications.

30. Barab, S., \& Squire, K. (2004). Design-based research: Putting a stake in the ground. Journal of Learning Sciences, 13(1), 1-14. Retrieved from https://website.education.wisc.edu/kdsquire/manuscripts/jlsbarab-squire-design.pdf

31. Herrington, J., McKenney, S., Reeves, T., \& Oliver, R. (2007). Designbased research and doctoral students: Guidelines for preparing a dissertation proposal. In C. Montgomery \& J. Seale (Eds.), Proceedings of the world conference on educational multimedia, hypermedia and telecommunications (4089-4097). Chesapeake, VA: Association for the Advancement of Computing in Education. Retrieved from http:// researchrepository.murdoch.edu.au/id/eprint/6762/

32. Glaser, B. G, \& Strauss, A. L. (1967). The discovery of grounded theory: Strategies for qualitative research. New York, NY: Adeline DeGruyter.

33. Creswell, J. W. (2012). Analyzing and interpreting qualitative data. In J. W. Creswell, Educational research: Planning, conducting, and evaluating quantiative and qualitative research (4th ed., 236-264). Boston, MA: Pearson Education.

34. DiSessa, A. (2006). A history of conceptual change reserch: Threads and fault lines. In R. K. Sawyer (Ed.), The Cambridge handbook of the learning sciences (2nd ed., 265-281). New York, NY: Cambridge University Press.

35. You, Y. (1993). What can we learn from chaos theory? An alternative approach to instructional systems design. Educational Technology Research and Development, 41(3), 17-32. Retrieved from https://link. springer.com/article/10.1007/BF02297355

36. Greeno, J. G. (2006). Learning in activity. In R. K. Sawyer (Ed.), The Cambridge handbook of the learning sciences (2nd ed., 79-96). New York, NY: Cambridge University Press.

37. Shea, P., Hayes, S., Uzuner-Smith, S., Gozza-Cohen, M., Vickers, J., \& Bidjerano, T. (2014). Reconceptualizing the community of inquiry framework: An exploratory analysis. Internet and Higher Education, 23, 9-17. doi: 10.1016/j.iheduc.2014.05.002
38. Suthers, D. D. (2006). Technology affordances for intersubjective meaning making: A research agenda for CSCL. International Journal of Computer-Supported Collaborative Learning, 1(3), 315-337. doi: 10.1007/s11412-006-9660-y

39. Krathwohl, D. R. (2002). A revision of Bloom's taxonomy: An overview. Theory into Practice, 41(4), 212-218. Retrieved from https://www. depauw.edu/files/resources/krathwohl.pdf

40. Andriessen, J., \& Barker, M. (2014). Arguing to learn. In R. K. Sawyer (Ed.), The Cambridge handbook of the learning sciences (2nd ed., 439460). New York, NY: Cambridge University Press.

41. Merriam, S. B., Cafffarella, R. S., \& Baumgartner, L. M. (2007). Learning in adulthood: A comprehensive guide (3rd ed.). San Francisco, CA: Jossey-Bass.

42. Wenger, E. (1998). Communities of practice: Learning, meaning, and identity. New York, NY: Cambridge University Press. 